\title{
Analysis of a Low-Angle Annular Expander Nozzle
}

\author{
Kyll Schomberg, ${ }^{1}$ John Olsen, ${ }^{1}$ and Graham Doig ${ }^{1,2}$ \\ ${ }^{1}$ School of Mechanical and Manufacturing Engineering, UNSW, Sydney, NSW 2052, Australia \\ ${ }^{2}$ Aerospace Engineering Department, California Polytechnic State University, San Luis Obispo, CA 93407, USA
}

Correspondence should be addressed to Kyll Schomberg; kyll.schomberg@unsw.edu.au

Received 16 October 2014; Accepted 10 March 2015

Academic Editor: Chao Tao

Copyright (C) 2015 Kyll Schomberg et al. This is an open access article distributed under the Creative Commons Attribution License, which permits unrestricted use, distribution, and reproduction in any medium, provided the original work is properly cited.

\begin{abstract}
An experimental and numerical analysis of a low-angle annular expander nozzle is presented to observe the variance in shock structure within the flow field. A RANS-based axisymmetric numerical model was used to evaluate flow characteristics and the model validated using experimental pressure readings and schlieren images. Results were compared with an equivalent convergingdiverging nozzle to determine the capability of the wake region in varying the effective area of a low-angle design. Comparison of schlieren images confirmed that shock closure occurred in the expander nozzle, prohibiting the wake region from affecting the area ratio. The findings show that a low angle of deflection is inherently unable to influence the effective area of an annular supersonic nozzle design.
\end{abstract}

\section{Introduction}

The substantial cost of transporting payload into orbit has created the demand for a reusable, single stage launch system. It has been estimated that a reusable single stage launch system has the potential to reduce the cost per kilogram to orbit by an order of magnitude [1]. Propulsion systems fitted with conventional convergent-divergent nozzles which operate from sea level to the vacuum conditions (Space Shuttle Main Engine, Vulcain, etc.) are currently subject to efficiency losses of up to $15 \%$ [2]. The fixed area ratio design employed in these nozzles produces efficiency losses by forcing the pressure of the exhaust at the nozzle exit plane to remain constant. Optimal nozzle efficiency is achieved when the pressure of the exhaust exiting the nozzle is equal to that of the receiver. As the receiver or local atmospheric pressure is a function of altitude, optimal efficiency is restricted to a single altitude for a fixed nozzle, with pressure losses incurred at all other altitudes. To increase the feasibility of single stage launch systems, techniques to compensate for the variation in atmospheric conditions are required. Nozzle concepts that compensate for this variation have existed in literature for over 50 years [3] and are generally classed with respect to the adaptive mechanism employed, that is, controlled flow separation devices $[4,5]$ and passive area variation nozzles $[6,7]$.
In a supersonic nozzle, flow separation occurs due to stagnation of the boundary layer as a result of a strong adverse pressure gradient at the nozzle wall [8]. Controlled flow separation devices attempt to vary the nozzle area ratio by intentionally inducing this phenomenon to reduce the effective exit area [4]. The static wall pressure at which the flow separates can be predicted with reasonable accuracy $[9,10]$. However, the process from "full-flowing" to separated flow conditions is not fully understood [11] and can induce high vibrational and thermal loads to the nozzle wall [12]. Additionally, this method of altitude compensation is inherently a "staged" process, only capable of reducing pressure losses through restricting the operating altitude range of each discrete stage [13]. Passive variable area nozzle concepts adapt for changing atmospheric pressure through a continual adjustment of the effective nozzle exit area and, therefore, a continual adjustment of the exhaust pressure at the nozzle exit plane. Variation of the effective area occurs through either an external (plug nozzle) [6] or an internal (expansiondeflection nozzle) [7] interaction between the supersonic exhaust with the receiver.

The variation of effective nozzle area is achieved by the manipulation of local atmospheric conditions. In the expansion-deflection nozzle, this process is facilitated through the use of a central flow deflector, commonly referred to as a pintle. The deflection of the supersonic exhaust radially 


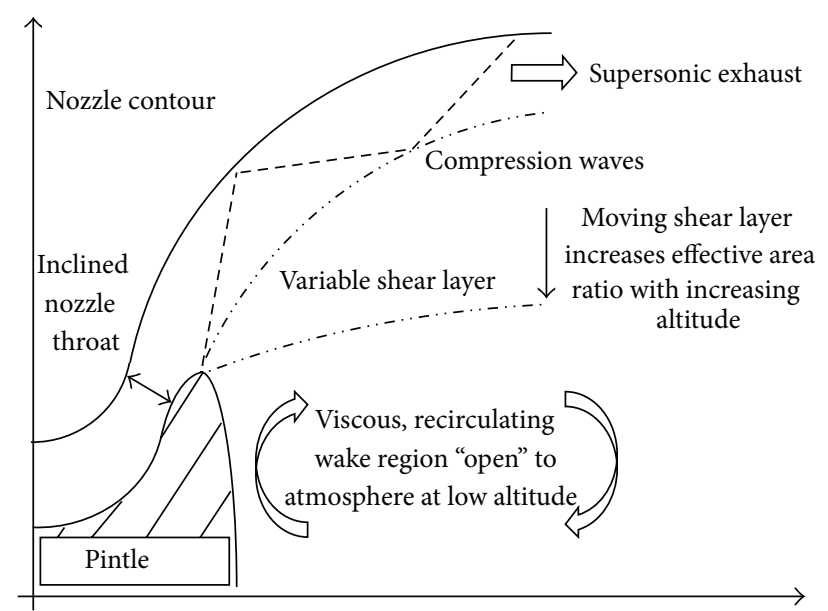

Figure 1: Half diametric cross section of the expansion-deflection nozzle behavior in open mode.

outwards towards the nozzle wall results in the creation of a wake region at the base of the pintle. The interaction between the subsonic, recirculating wake, and supersonic exhaust produces a shear layer which acts to vary the effective area ratio of the nozzle and limit expansion of the exhaust flow. The location of the shear layer and effective area ratio are determined by the pressure of the wake area. In altitude compensating or "open wake" mode, the pressure of the wake region is theoretically equal to the local atmospheric pressure [7]. Therefore, during open wake operation the location of the shear layer will ideally ensure optimal expansion of the exhaust respective to ambient conditions. The wake area is largest at high receiver pressure and reduces as receiver pressure decreases. This increases the effective nozzle area ratio until the physically defined maximum is reached. Operation at the physically defined area represents the design point of the nozzle and further reduction in receiver pressure results in an operational transition to nonaltitude compensating or "closed wake" mode. Nozzle behavior during closed mode operation is equivalent to a fixed area converging-diverging (CD) nozzle and can be modeled using conventional supersonic flow theory. Variations in expansion-deflection nozzle behavior during "open" and "closed" operating modes are shown in Figures 1 and 2.

The plug and truncated plug (aerospike) nozzle have arguably received the most attention out of all altitudeadaptive nozzle concepts irrespective of the large base drag, increased heat flux, and variation in thrust levels at transonic velocities [14]. The preference of the plug nozzle over the expansion-deflection nozzle appears to have stemmed from a report on an early investigation into variable area nozzles [15]. This report concluded that the altitude adaptive potential of the expansion-deflection nozzle was low, roughly equivalent to a conventional converging-diverging (CD) nozzle. However, it should be noted that the expansion-deflection nozzle utilized in [15] appeared to follow design principals consistent with Mueller et al. [16] as opposed to Rao, the developer of the expansion-deflection concept [7]. This is significant because Mueller's work involved instigating an early transition from

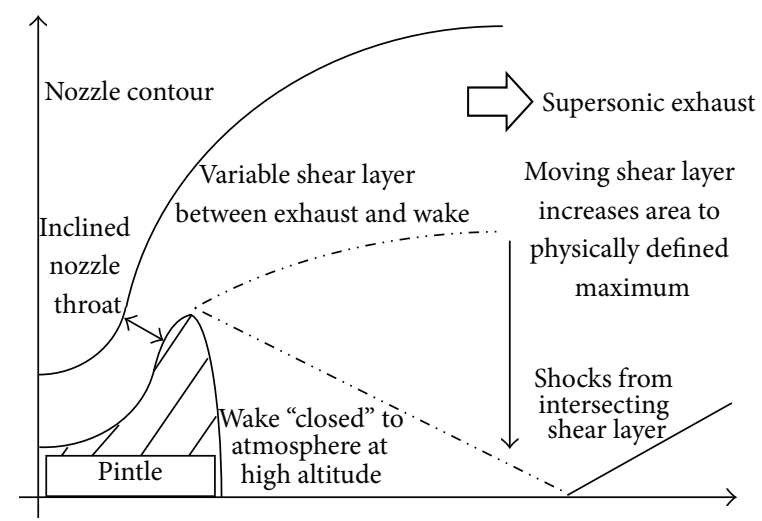

FIGURE 2: Half diametric cross section of the expansion-deflection nozzle behavior in closed mode.

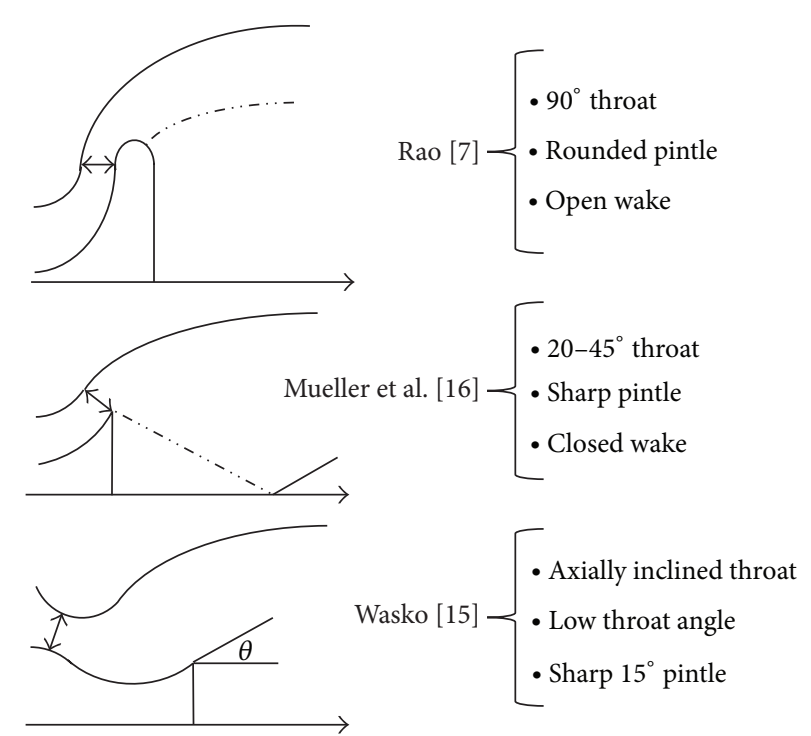

Figure 3: Expansion-deflection nozzle design comparison.

open to closed wake mode, therefore producing a design inherently unable to compensate for altitude. A comparison of expansion-deflection nozzle designs is shown in Figure 3.

In the present work, a low-angle annular expander nozzle has been designed using similar principals to a Wasko expansion-deflection nozzle. Evidence of wake closure during "open mode" operation would confirm that results obtained in [15] were a function of the design used as opposed to an inherent flaw within the expansion-deflection nozzle concept. In this work, the operating pressure ratio was kept within the overexpanded regime to maintain nozzle operation in "open wake" or altitude compensating mode. To generate numerical results, computational fluid dynamics (CFD) methods were selected over the traditional method of characteristics due to the capability of CFD in describing all flow regions within the nozzle. The method of characteristics is limited to inviscid, supersonic flow fields and breaks down in the subsonic, viscous wake. Accurate modeling of wake behavior is therefore imperative due to the considerable effect 
this region has on the overall nozzle flow and therefore the capability of the wake region in influencing effect nozzle area.

\section{Design Methodology}

All of the experimental work was conducted in the aerodynamics laboratory at UNSW, Australia. Dry air at a maximum stagnation pressure of $700 \mathrm{kPa}$ was used as the test fluid. The receiver pressure was fixed for all tests at the value of local atmospheric pressure. A baseline pressure ratio of five was used to initiate the design process as the stagnation pressure could be varied above and below this value to observe nozzle behavior over a theoretical altitude range. Nozzle operation was kept to overexpanded (OX) and grossly overexpanded flow conditions (GOX). In this work, GOX flow was defined as nozzle operation at a pressure ratio lower than that required for flow separation. This was achieved by applying Summerfield's criteria [9] to the baseline pressure ratio to yield a design pressure ratio. The corresponding nozzle area ratio was determined from the design pressure ratio assuming isentropic flow conditions. This assumption is commonly used for supersonic nozzles in the design phase [2] and was deemed to be satisfactory for this purpose as relative nozzle behavior was the performance measure in this work.

The nozzle throat was sized with respect to the flow rate of the compressor and to ensure a sufficient area ratio to allow the assumption of stagnation conditions at the inlet. The nozzle throat radius $\left(r_{t}\right)$ was determined through assuming isentropic flow, continuity, and sonic conditions at the throat and a value of $0.015 \mathrm{~m}$ was used. The difference between inlet flow parameters from stagnation values was estimated from the area ratio of 12 between the inlet and throat and found to be less than $0.2 \%$. This value was deemed sufficient to enable stagnation conditions to be assumed at the nozzle inlet and quarter circle of radius $2.67 r_{t}$ was used to construct the convergent section. A divergence contour at a constant angle of $10^{\circ}$ and total area ratio of 2.34 was utilized for the expansion section of the nozzle.

The fixed geometrical inlet required an unconventional rig design to achieve the required nozzle geometry. A pintle attachment was placed upstream of the nozzle and fixed using a strut-based support structure. Although the velocity at the inlet was relatively low $\left(<15 \mathrm{~ms}^{-1}\right)$ and the attachment support structure aerodynamically shaped to reduce flow interference, it was decided to use an annular CD nozzle to negate any bias caused by the attachment. A pintle diameter of $0.8 r_{t}$ was used to satisfy a factor of safety of 10 for this connection. Following the throat area, the cross sectional area of the CD pintle attachment was gradually reduced to a point. Comparatively, in the expander nozzle, the pintle diameter was increased downstream of the throat and encompassed a sharp trailing edge, consistent with the design of Wasko [15]. A ratio of pintle base to nozzle exit area of $10 \%$ was used for the expander configuration, resulting in a postthroat length of $1.3 r_{t}$. Figure 4 shows the conventional (CD) and expander (ED) nozzle configurations.

All schlieren images were obtained using a vertical knife edge z-type setup. A mercury lamp was used as the light

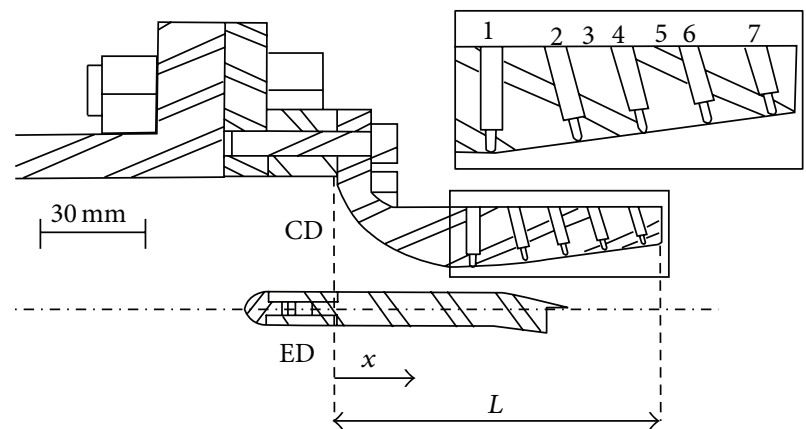

FIGURE 4: Half diametric sectioned view of the CD and ED nozzle configurations.

source in conjunction with two $60^{\prime \prime}$ astronomical grade focal mirrors and a 50\% cut-off filter. Images were captured by Photron FASTCAM high speed camera recording images at a resolution of $1024 \times 1024$ pixels at $3000 \mathrm{fps}$. Static pressure values were taken directly from analogue gauge readings after the nozzle flow had stabilized. The $1 \mathrm{~mm}$ diameter tapping ports were spaced at $10 \mathrm{~mm}$ increments in the axial direction so as not to affect flow structure. Tapping locations 3 and 5 were offset by $90^{\circ}$ to increase the number of overall readings. All tapping locations were duplicated at $180^{\circ}$ to enable an average pressure value to be taken between both points. The importance of the throat and exit pressure reading warranted a tapping on each $90^{\circ}$ axis and an average was taken over the four total readings. Sources of experimental error in the static pressure readings were quantified using the calibration error and incremental errors in the gauge readings and were found to be $4 \%$. To accommodate a tapping at the theoretical nozzle exit, the divergent section was extended by approximately $5 \mathrm{~mm}$. Although this modification would introduce additional expansion of the flow field and affect the exit shock pattern, it was deemed necessary to ensure an adequate pressure distribution throughout the divergent section.

\section{Numerical Model}

All numerical results were generated through the commercially available ANSYS Fluent 14.5 software. Fluid flow through both nozzle configurations was treated as compressible and turbulent. The boundary conditions were consistent with the pressure values recorded during experiments and implemented using a pressure inlet and outlet for all numerical models. A time or Reynolds averaged (RANS) approach to turbulence modelling was adopted due to the relatively steady nature of a full-flowing nozzle and the reduced computational expense required. Initial turbulence parameters were derived from the Reynolds number and boundary layer thickness at the nozzle inlet and calculated using a turbulent intensity of $3.6 \%$ and length scale of $1.68 \mathrm{~mm}$. Due to the low stagnation enthalpy, air was modelled as ideal gas and a three-coefficient Sutherland model was used for viscosity [17].

The axisymmetric pressure-based coupled solver was used in conjunction with second order spatial discretization 


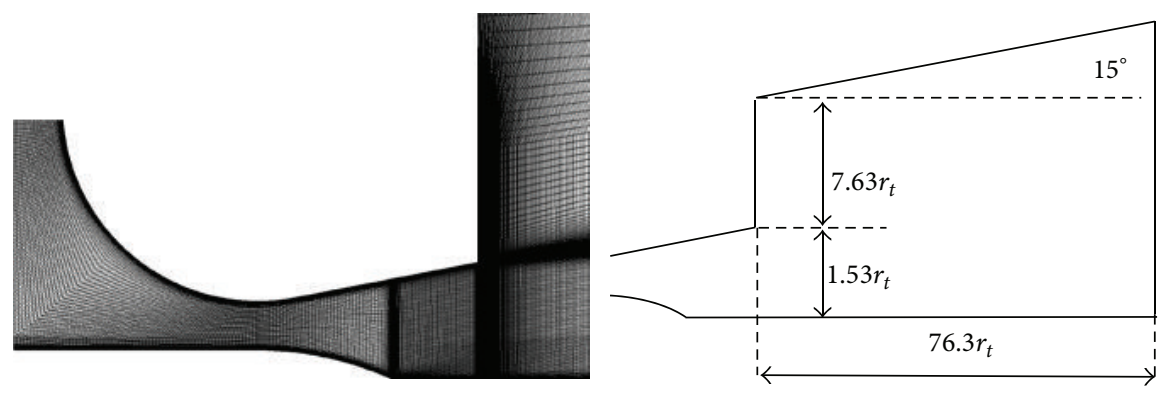

FIGURE 5: Mesh structure and downstream exhaust flow domain.

schemes for all calculations. Surface monitors were set on the nozzle inlet, nozzle exit, and outflow domains to record the mass flow rate in addition to the static pressure and velocity magnitude at the nozzle exit. Convergence was deemed to have been achieved when the values at each surface monitor changed by less than $0.1 \%$ over 500 iterations. Additionally, a variation of mass flux of less than $0.1 \%$ between the inlet and outlet was required to satisfy continuity through the domain. The geometric domain was consistent between all models excluding the pintle. The effects of the nose cone and attachment struts on the flow field were assessed in a preliminary analysis and found to be negligible. This enabled the geometry to be simplified to an axisymmetric configuration to aid in the discretization process. The outflow region was sized in order to ensure the effect of domain boundaries on the flow was negligible. A fully structured spatial discretization scheme comprised of quadrilateral cells was used for all models. Figure 5 details the mesh structure and dimensions of the downstream exhaust region used in all models. As all nozzle operation was exclusively within the overexpanded regime, strong pressure gradients were expected to be present at the nozzle wall. To ensure that flow behavior under these conditions could be modelled accurately, the first cell height was controlled to maintain a nondimensional wall distance $(y+)$ of 1 .

3.1. Grid Convergence. A comparison of experimental and numerical static pressure readings and schlieren images was used to determine independence of grid density. Refinement of grid between levels was achieved by progressively splitting each cell in the numerical domain into four and resulted in a cell count of $0.9,3.6$, and $14.4 \times 10^{5}$ for the coarse, standard, and fine mesh levels, respectively. Strategic refinement of the coarse and standard grids was used to determine if the accuracy of the predicted shock structure could be improved at a greatly reduced computational cost. This was achieved by calculating the pressure gradient between cells and splitting all individual cells if the normalized pressure gradient was greater than 0.05 . This process was completed twice after convergence had been achieved and approximately doubled the cell count in the coarse and standard grids, denoted by coarse (refined) and standard (refined), respectively.

The turbulence model used for all GCI calculations was the Spalart-Allmaras (SA) model, a one-equation turbulence model developed specifically for aerodynamic flow fields

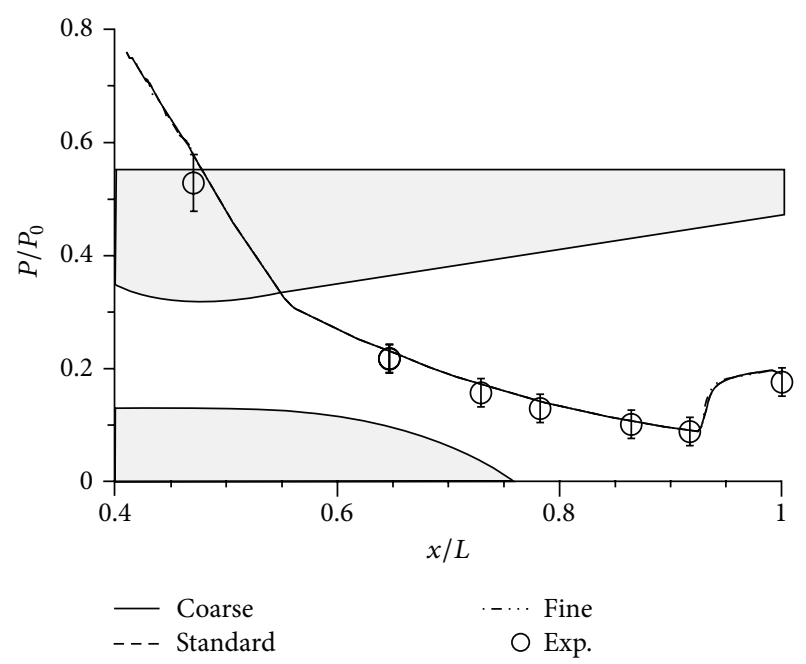

FIGURE 6: Effect of mesh refinement on the static pressure distribution.

involving wall bounded flows [18]. The SA model was considered suitable for this purpose due its proven capability of accurately modeling complex flows involving shock waves [19-23]. The CD GOX case was used for the GCI due to the known close correlation of a CD nozzle with analytical results [24]. Errors in experimental pressure readings were quantified through consideration of gauge calibration error, pressure increment spacing, and the known manufacturing tolerance of $\pm 0.15 \mathrm{~mm}$. The effect of grid density on pressure distribution and numerical schlieren is shown in Figures 6 and 7 , respectively.

Variation between numerical pressure distributions was minimal across all levels of refinement. Inspection of the location of flow separation showed that the coarse distribution was predicted $1 \%$ earlier. This discrepancy was annulled through refinement of the coarse mesh.

The effect of mesh refinement on predicted shock structures was significant. Shock resolution in the coarse mesh was greatly increased throughout the refinement process. This process was seen to fully develop the cap shock pattern in both the coarse and standard mesh levels. The refined coarse mesh was used for all future simulations due to the greatly reduced computational time, small numerical uncertainty 


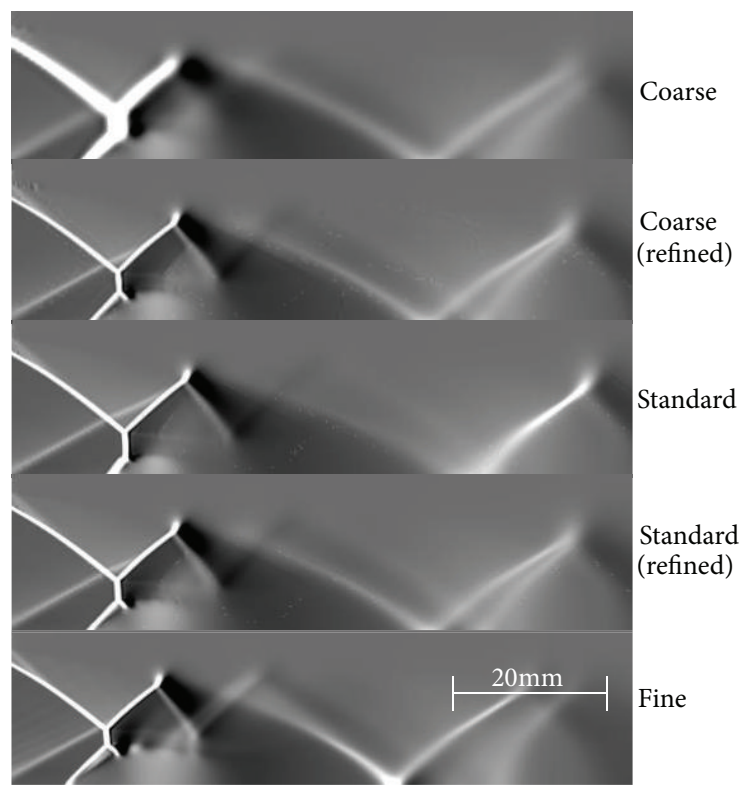

FIGURE 7: Effect of mesh refinement on the predicted shock structure.

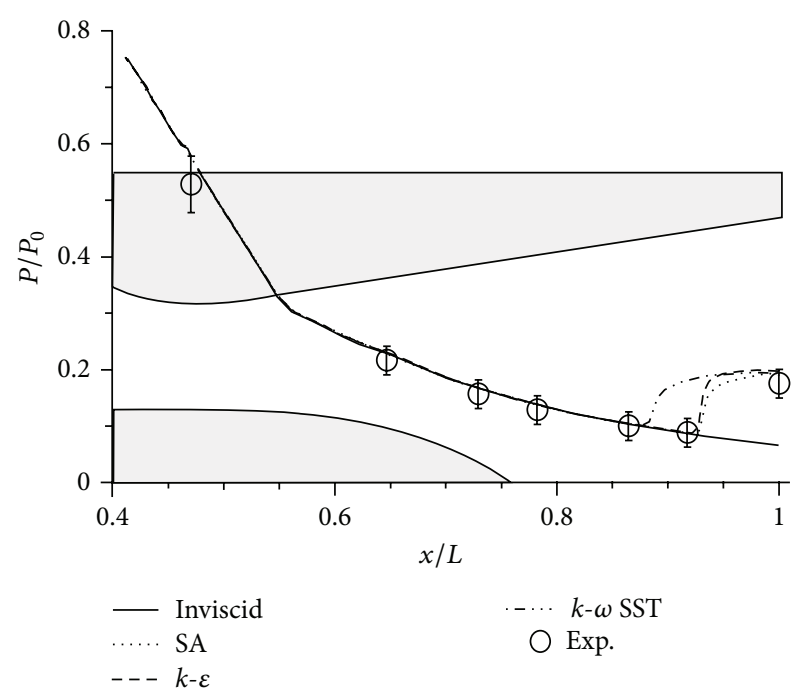

FIGURE 8: Effect of turbulence model on the pressure distribution.

predicted in the shock structure, and negligible difference in the pressure distribution.

3.2. Turbulence Modelling. To assess the influence of modeled turbulence in the flow field, the SA model was compared to the $k$ - $\omega$ shear stress transport model [25] ( $k-\omega$ SST) and the $k-\varepsilon$ realizable model [26] $(k-\varepsilon)$, both of which have been used in previous work to model similar flow fields [27]. In addition to varying the turbulence model, an inviscid solution was compared to assess the influence of turbulence itself within the flow field. Figures 8 and 9 outline the effect of turbulence model variation on the pressure distribution and predicted shock structure.

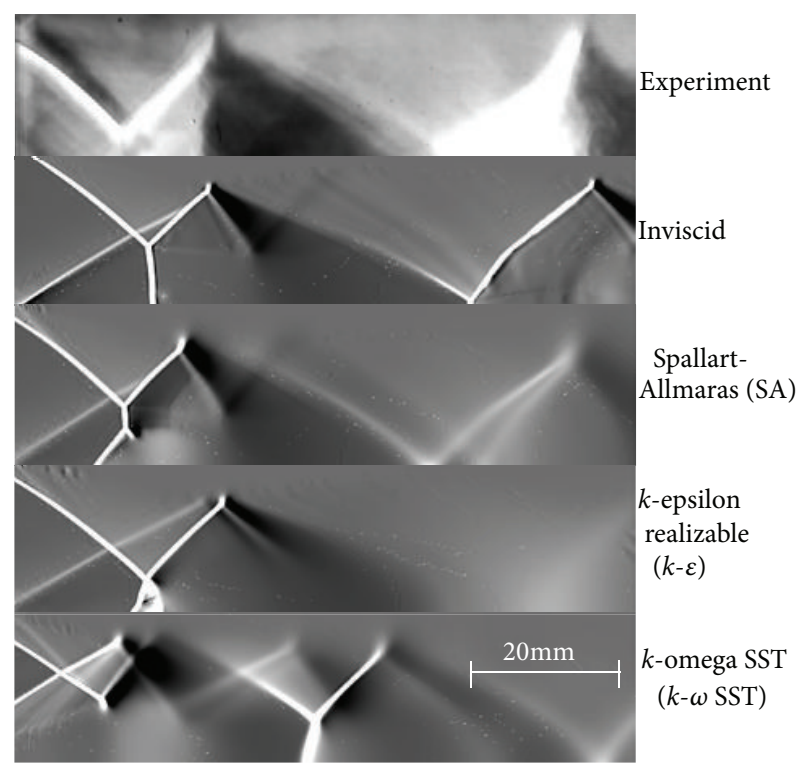

FIGURE 9: Effect of turbulence model on the predicted shock structure.

The selection of the turbulence closure model had a considerable effect on the predicted flow field structure. The inviscid solution did not predict flow separation, whereas the $k-\omega$ SST solution prematurely predicted separation compared to the experimental values. A large variation in numerical schlieren was evident between all models, highlighting the salient effect of turbulence within the flow field. A numerically generated secondary shock was present in all models. This effect was considerable in the $k-\omega$ SST solution and appeared to cause dissipation of the Mach disk. Numerical diffusion in the $k-\varepsilon$ realizable resulted in low resolution of the flow structure, particularly in the secondary shock diamond. The SA turbulence model was therefore selected for use in all future calculations due to the close correlation with experimental pressure values, increased shock structure detail, and high computational efficiency.

\section{Results and Discussion}

4.1. Grossly Overexpanded (GOX) Condition. Under GOX flow conditions, separation was expected to occur in the CD configuration. Theoretically, separation should be avoided under all conditions in a functional expander-type nozzle due to influence of the wake region. However, wake closure would produce flow characteristics equivalent to the CD nozzle. The measured stagnation pressures were 4.90 and 4.42 atm in the $\mathrm{CD}$ and expander (ED) configurations, respectively. Figures 10-12 compare numerical and experimental pressure distributions and schlieren images.

The numerical pressure distributions were within the experimental tolerances in both configurations. Flow separation occurred at $x / L=0.925$ for both models, inferring favorable flow conditions in the ED nozzle relative to the lower stagnation pressure. Increased postthroat pressure values in the ED nozzle were caused by the formation of 


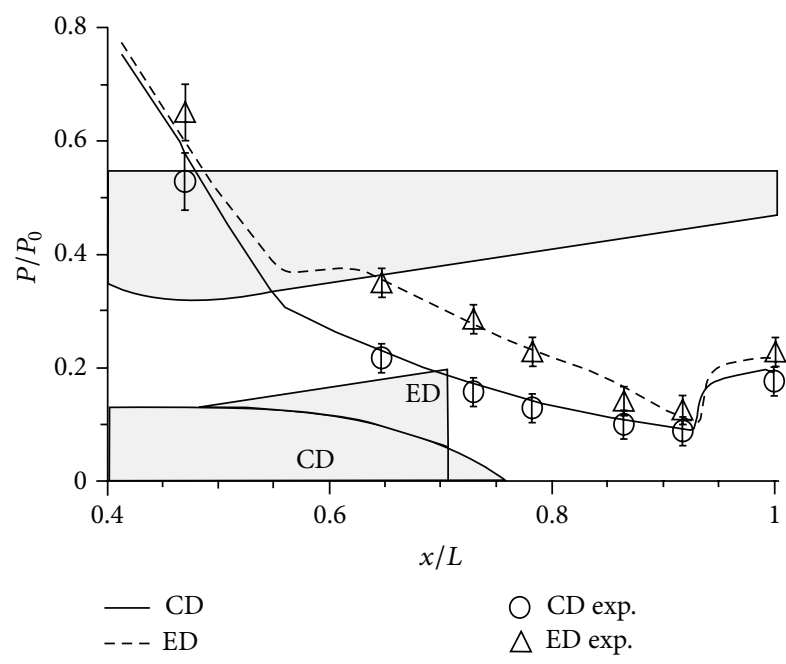

FIGURE 10: Comparison of pressure distributions in the GOX flow condition.

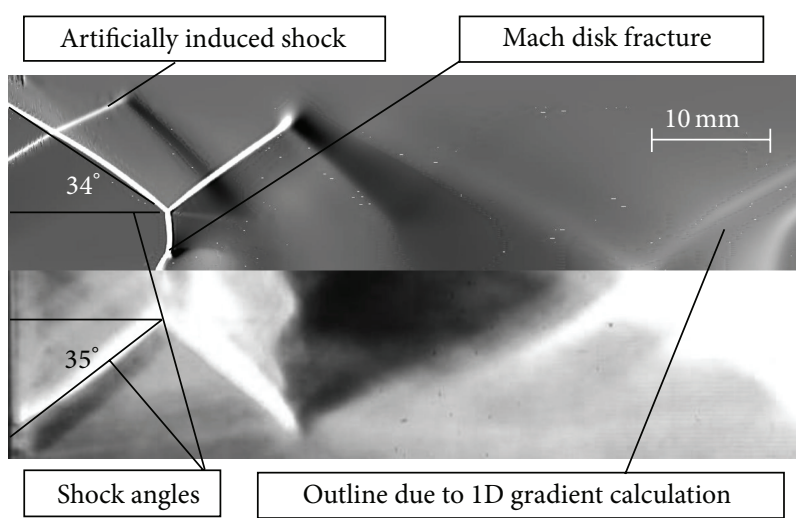

FIgURE 11: Comparison of CD schlieren images in the GOX flow condition.

compression waves and a reduced rate of area ratio increase as a result of the pintle geometry. The discrepancy between the shock diamond shadings was a result of the calculation of density gradient explicitly in the longitudinal direction. Measured shock angles were within $2^{\circ}$ for both configurations, where a higher shock angle in the ED configuration was indicative of the lower stagnation pressure. The distortion of a visible Mach disk evident in the ED configuration would be expected within a wake-embedded flow field. However, the intersection of shock diamonds with the flow axis downstream showed that wake itself was "closed" and that nozzle behavior was within the nonaltitude compensating regime. The secondary or trailing shock wave was a result of the sharp pintle edge, known to artificially induce wake closure [16].

4.2. Overexpanded (OX) Condition. Theoretically, flow separation should be avoided when either nozzle operates under general OX conditions [9]. However, it is important to note that the inherent instability of flow separation makes accurate prediction difficult [11] and that the purely empirical Summerfield's criterion [9] is unable to account for

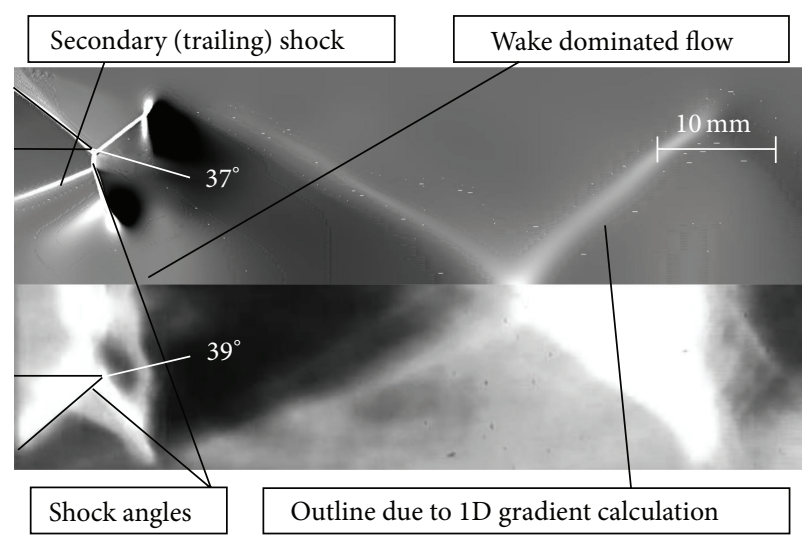

FIgUre 12: Comparison of ED schlieren images in the GOX flow condition.

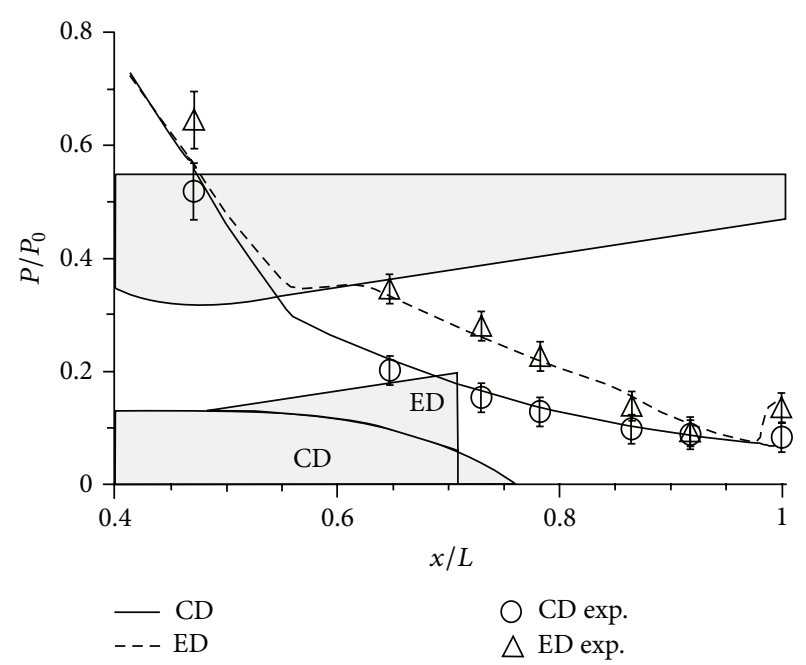

FIGURE 13: Comparison of pressure distributions in the OX condition.

the amplification of boundary layer aggravation present in low Mach number flows [27]. The measured stagnation pressures were 6.33 and $6.46 \mathrm{~atm}$ in the $\mathrm{CD}$ and $\mathrm{ED}$ configurations, respectively. Figures 13-15 compare numerical and experimental pressure distributions and schlieren images.

A close correlation between numerical pressure distributions and experimental values was again observed, with the main discrepancy located within the throat region in both configurations. Flow separation occurred within the ED model and was avoided in the CD model irrespective of the higher ED stagnation pressure. The location of the primary shock was within $2^{\circ}$ between models, with a lower shock angle present in the nonseparating CD nozzle. A fracture in the Mach disk was consistent with the GOX results in the CD configuration. The existence of a Mach disk in the ED nozzle represented a shock-dominated flow field. An artificially induced shock was again present in the CD nozzle, whereas the trailing shock generated from postpintle expansion caused a secondary shock in the ED nozzle. No evidence of a wake area was evident in the ED model, 


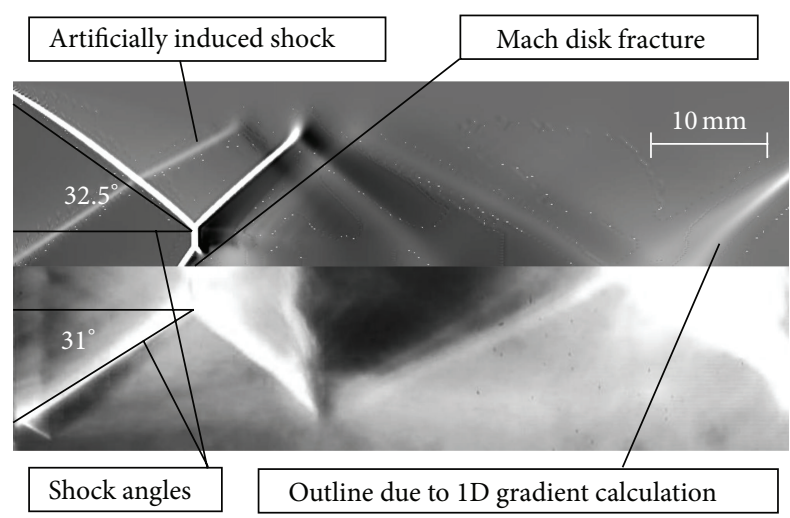

FIGURE 14: Comparison of CD schlieren images in the OX flow condition.

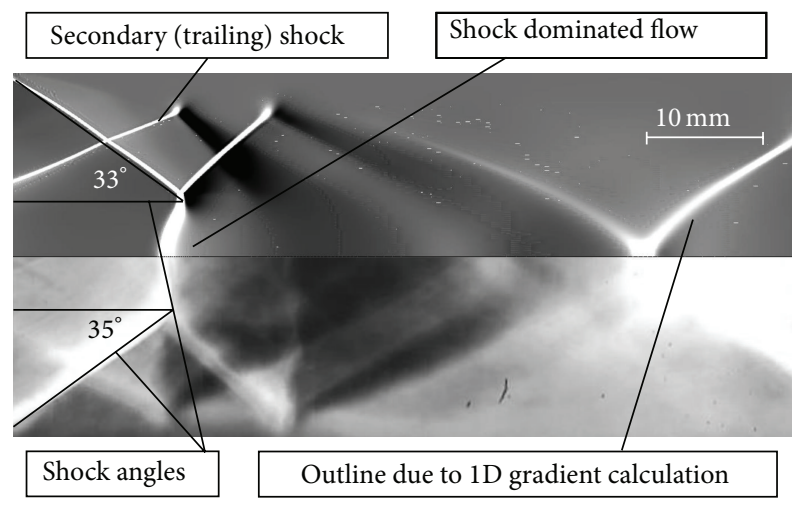

FIGURE 15: Comparison of ED schlieren images in the OX flow condition.

confirming that operation of the configuration was in "closed mode" and that performance equivalent to a CD nozzle was expected.

\section{Conclusions}

A low-angle expander nozzle has been experimentally and numerically compared to a CD nozzle at an OX and GOX pressure operating condition. Verification and validation of the RANS-based numerical model indicated that the variation in static pressure distribution with respect to grid density was low. Comparatively, grid density had a direct effect on shock resolution. A targeted approach to grid refinement using the normalized pressure gradient between cells represented the flow for minimal computational cost. Selection of turbulence model had a considerable effect on the numerical solution, affecting both the separation point of the flow and the shock structure within the nozzle flow field. This was particularly evident in the description of the quasiopen wake flow field observed in the expander nozzle at GOX conditions.

The experimental and numerical static pressure distributions were within experimental uncertainty values at both operating conditions in the CD and expander nozzles. Premature wake closure was observed in the expander nozzle at the GOX operating condition by comparing schlieren images, confirming that the influence of the wake region of the effective area of the expander nozzle was low. The consistent static pressure values at the nozzle exit and distribution throughout the divergence section suggested flow behavior in the expander nozzle configuration was largely independent of the level of overexpansion. The results highlight the limitations of a low-angle flow deflector in generating a wake region that is capable of varying the effective area of a supersonic nozzle. Use of a low-angle expander design should therefore be avoided for use in altitude-adaptive nozzle concepts, such as the expansion-deflection nozzle.

\section{Conflict of Interests}

The authors declare that there is no conflict of interests regarding the publication of this paper.

\section{Acknowledgments}

The authors would like to acknowledge Mr. Charles Queriaud for his assistance with the experimental schlieren imagery and Mr. Terry Flynn for his assistance with setting up the experimental rig and obtaining experimental pressures. The contributions of Mr. Ian Cassapi, Mr. Andrew Higley, and Mr. Seetha Mahadeven in the manufacture of all experimental components are also acknowledged.

\section{References}

[1] N. V. Taylor, C. M. Hempsell, J. Macfarlane et al., "Experimental investigation of the evacuation effect in expansion deflection nozzles," Acta Astronautica, vol. 66, no. 3-4, pp. 550-562, 2010.

[2] G. P. Sutton and O. Biblarz, Rocket Propulsion Elements, chapter 2, 3, John Wiley \& Sons, New York, NY, USA, 7th edition, 2001.

[3] G. V. Rao, "Recent developments in rocket nozzle configurations," ARS Journal, vol. 31, no. 11, pp. 1488-1494, 1961.

[4] M. Horn and S. Fisher, "Dual-bell altitude compensating nozzles,” NASA CR-194719, National Aeronautics and Space Administration, 1994.

[5] G. Hagemann, D. Manski, and G. Krulle, "Dual expander engine flowfield simulations," in Proceedings of the 31st Joint Propulsion Conference and Exhibit, AIAA 95-3135, AIAA, San Diego, Calif, USA, 1995.

[6] G. V. R. Rao, "Spike nozzle contour for optimum thrust," Ballistic Missile and Space Technology, vol. 2, pp. 92-101, 1961.

[7] G. V. R. Rao, "Analysis of a new concept rocket nozzle," Journal of Liquid Rockets and Propellants, vol. 2, pp. 669-682, 1960.

[8] E. L. Morrisette and T. J. Goldberg, “Turbulent flow separation for overexpanded nozzles," NASA Technical Paper 1207, 1978.

[9] M. Summerfield, C. Foster, and N. Swan, "Flow separation in overexpanded supersonic exhaust nozzles," Journal of Propulsion, vol. 24, no. 9, pp. 319-321, 1954.

[10] R. H. Schmucker, "Status of flow separation prediction in liquid propellant rocket nozzles," NASA N75-12061/8, 1974.

[11] J. Ostlund, Supersonic flow separation with application to rocket engine nozzles [Ph.D. thesis], Royal Institute of Technology, Stockholm, Sweden, 2004. 
[12] M. Onofri and F. Nasuti, "The physical origins of side loads in rocket nozzles," in Proceedings of the 35th Joint Propulsion Conference and Exhibit, AIAA, Los Angeles, Calif, USA, 1999.

[13] G. Hagemann, M. Frey, and D. Manski, "A critical assessment of dual-bell nozzles," in Proceedings of the 33rd Joint Propulsion Conference and Exhibit, 3299, p. 3297, Seattle, Wash ,USA, 1997.

[14] G. Hagemann, H. Immicht, M. Terhardt, and G. Dumnov, "Critical assessment of the linear plug nozzle concept," in Proceedings of the AIAA 37th Joint Propulsion Conference and Exhibit, AIAA 2001-3683, Salt Lake City, Utah, USA, July 2001.

[15] R. A. Wasko, "Performance of annular plug and expansiondeflection nozzles including external flow effects at transonic mach numbers," NASA TN D-4462, 1968.

[16] T. J. Mueller, W. P. Sule, and C. R. Hall, "Characteristics of separated flow regions within altitude compensating nozzles variation," UNDAS TN-029-FR-9, University of Notre Dame, 1971.

[17] W. Sutherland, "The viscosity of gases and molecular force," Philosophical Magazine, vol. 36, pp. 507-531, 1893.

[18] P. Spalart and S. Allmaras, "A one-equation turbulence model for aerodynamic flows," La Recherche Aerospatiale, vol. 1, no. 5, pp. 5-21, 1992.

[19] G. C. Doig, T. J. Barber, E. Leonardi, A. J. Neely, and H. Kleine, "Methods for investigating supersonic ground effect in a blowdown wind tunnel," Shock Waves, vol. 18, no. 2, pp. 155-159, 2008.

[20] G. Doig, T. J. Barber, E. Leonardi, A. J. Neely, H. Kleine, and F. Coton, "Aerodynamics of a supersonic projectile in proximity to a solid surface," AIAA Journal, vol. 48, no. 12, pp. 2916-2930, 2010.

[21] G. Doig, "Transonic and supersonic ground effect aerodynamics," Progress in Aerospace Sciences, vol. 69, pp. 1-28, 2014.

[22] K. Schomberg and J. Olsen, "Altitude compensation in expansion deflection nozzles," in Proceedings of the 18th Australian Fluid Mechanics Conference, Launceston, Australia, 2012.

[23] F. R. Menter, "Two-equation eddy-viscosity turbulence models for engineering applications," AIAA Journal, vol. 32, no. 8, pp. 1598-1605, 1994.

[24] T. H. Shih, W. W. Liou, A. Shabbir, and J. Zhu, "A new k-epsilon eddy-viscosity model for high Reynolds number turbulent flows-model development and validation," Computers Fluids, vol. 24, no. 3, pp. 227-238, 1995.

[25] G. Hagemann, R. Schwane, P. Reijasse, and J. Ruf, "Nato TRO WG 10-CFD results of plug nozzle test cases," in Proceedings of the 38th AIAA/ASME/SAE/ASEE Joint Propulsion Conference and Exhibit, AIAA 2002-4036, Indianapolis, Ind, USA, 2002.

[26] T. J. Mueller, "Determination of the turbulent base pressure in supersonic axisymmetric flow," in Proceedings of the $3 \mathrm{rd}$ Propulsion Joint Specialist Conference, AIAA paper 67-446, Washington, DC, USA, 1967.

[27] R. H. Stark, "Flow separation in rocket nozzles, a simple criteria," in Proceedings of the 41st Joint Propulsion Conference and Exhibit, AIAA 2005-3940, AIAA, Tuscon, Ariz, USA, 2005. 

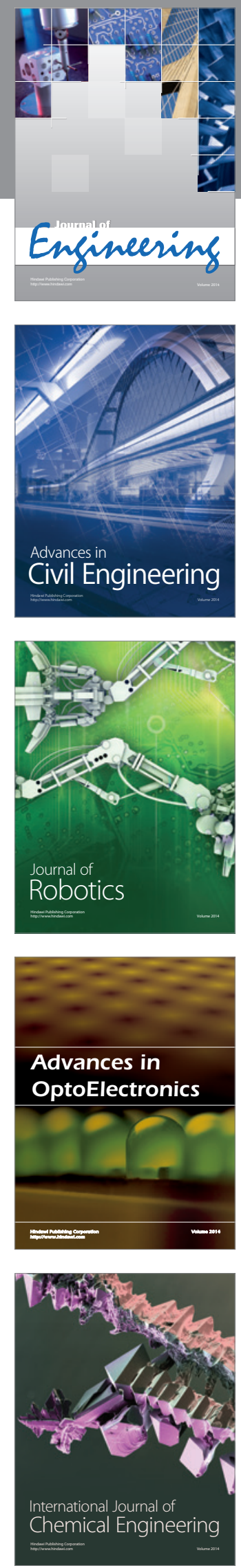

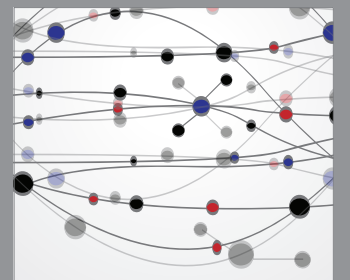

The Scientific World Journal
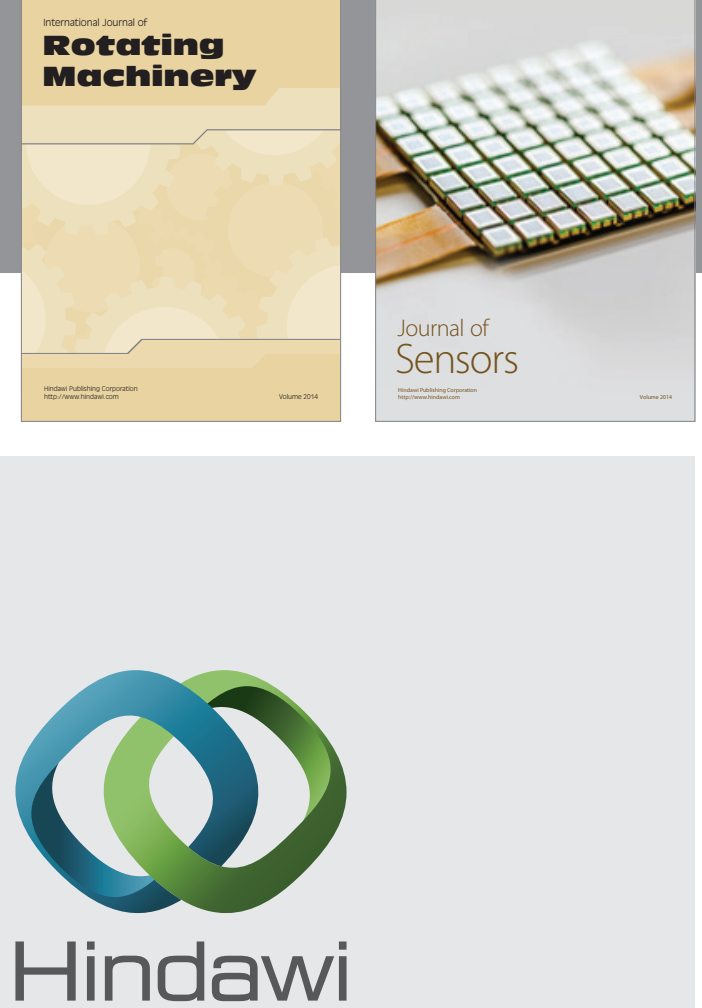

Submit your manuscripts at http://www.hindawi.com
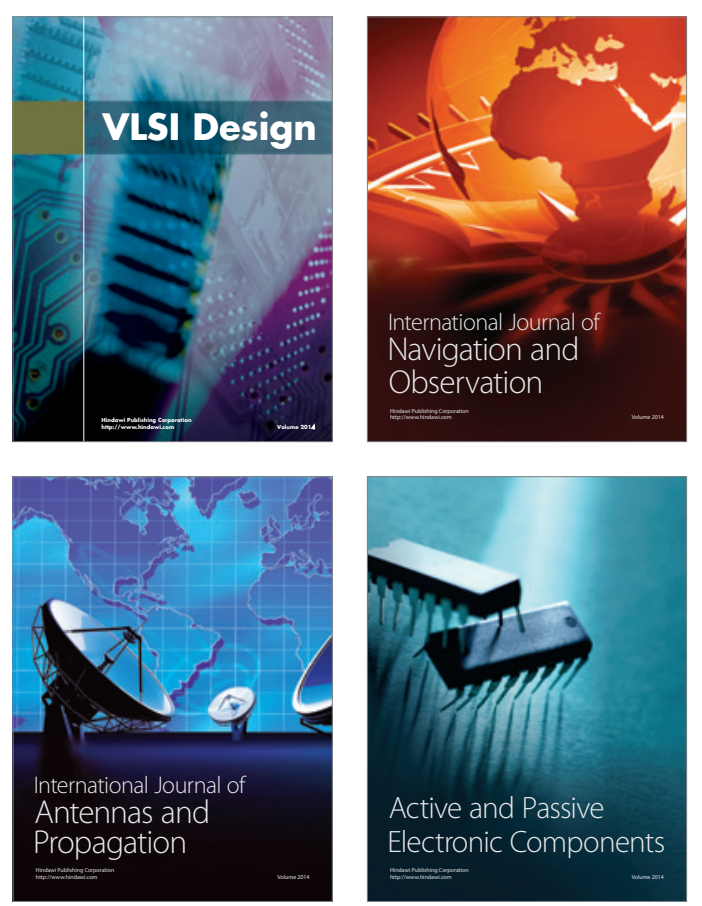
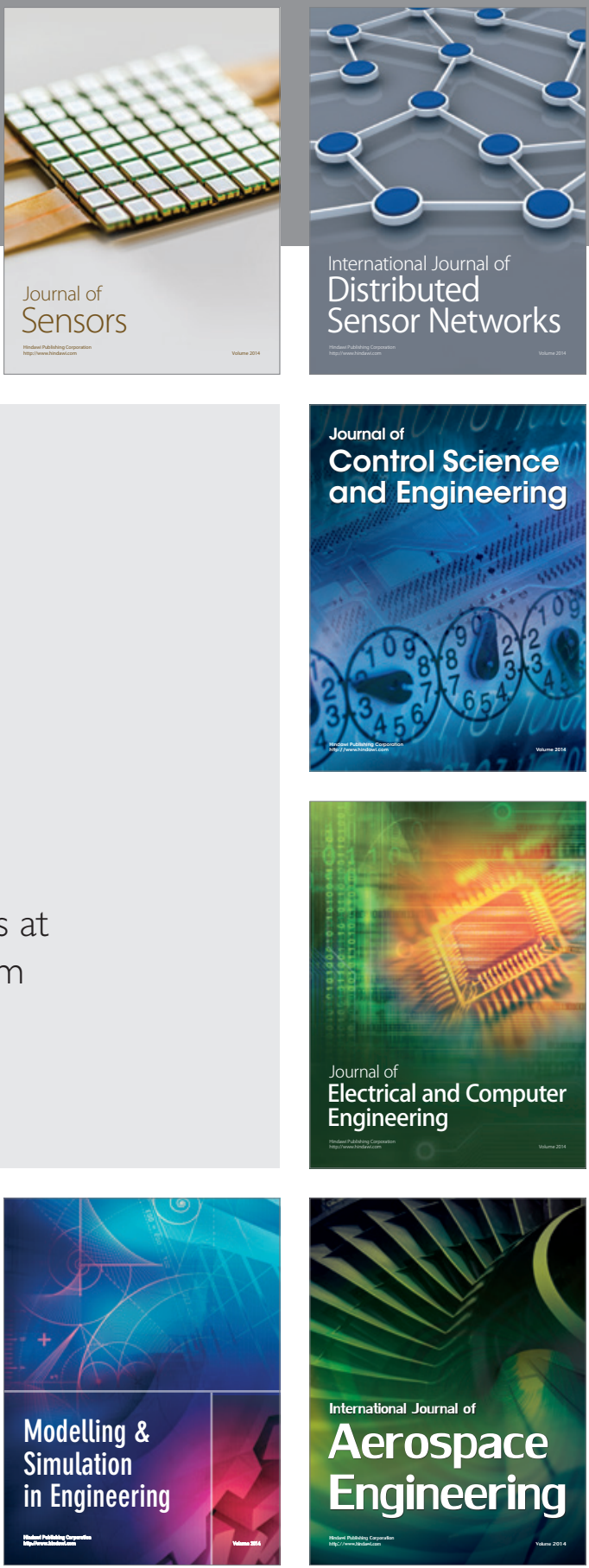

Journal of

Control Science

and Engineering
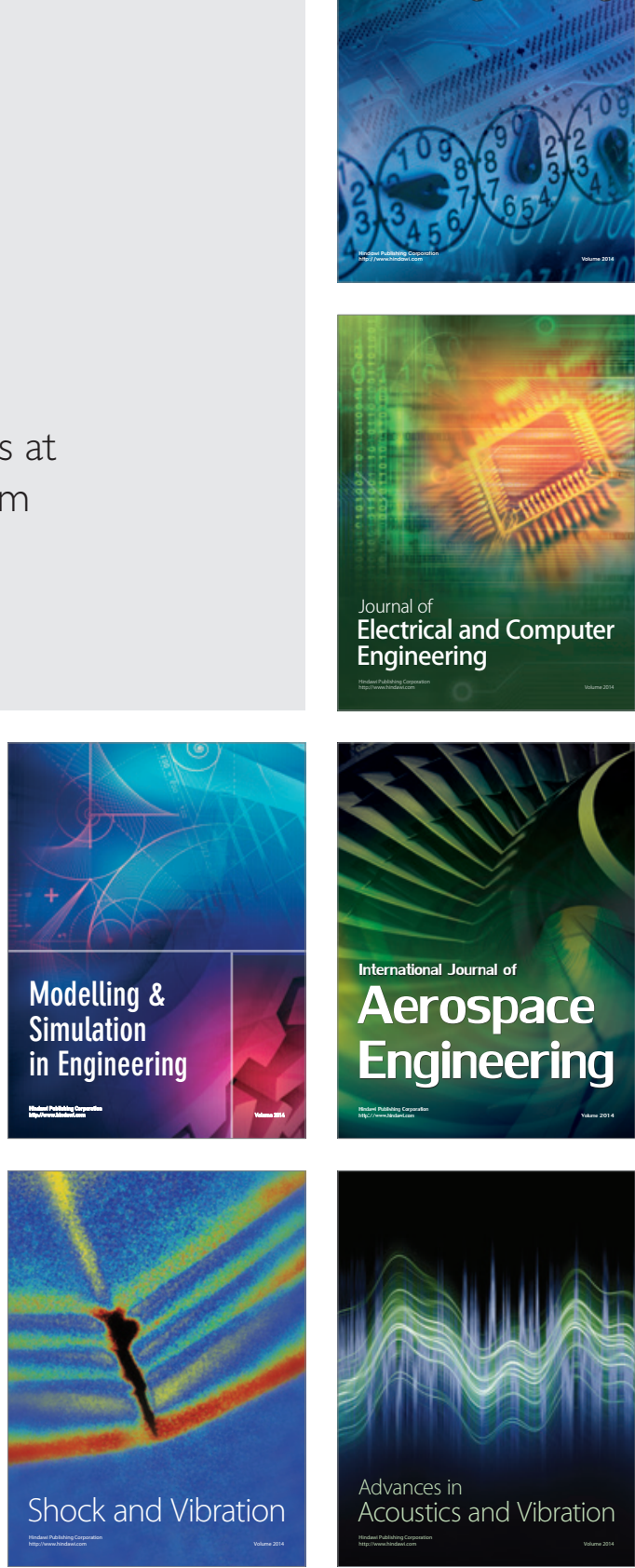